\title{
Adaptation and Effects of Social Media in Teaching and Learning at the Second Cycle Institution Level in Ghana
}

\author{
Doris Dore-Natteh \\ Namong Senior High School \\ Namong, Offinso \\ Ashanti Region, Ghana
}

\author{
Najim Ussiph \\ Department of Computer Science \\ Kwame Nkrumah University of Science \\ and Technology, Kumasi. Ghana
}

\begin{abstract}
The proliferation of social media platforms freely accessible online using mobile devices and the immense interest of this generation of students in such platforms to the detriment of their studies has cause for concern. Therefore, it becomes imperative to find a way to make them use the social media for useful purposes. The primary reason for this study is to determine the feasibility of adapting the use of social media in teaching and learning; and to assess the effectiveness and efficiency of these media for instructional engagement by instructors and learners at the second cycle institution level in Ghana. In the course of the study, Facebook $\odot$ and WhatsApp@ $\odot$ were used to supplement traditional classroom instruction and the impacts on students' motivation, performance and learning experience were assessed. Qualitative Case Study research method was used for this study. The results of the study demonstrate positive results in the use of the social media (Facebook and WhatsApp) to augment classroom teaching and learning with respect to students' motivation, performance and learning experience suggesting effectiveness and efficiency of the instructional blend. Implication of the results is that the findings can be utilized as a reference for educators and curriculum designers to find meaningful use of social media for teaching and learning in second cycle institutions in Ghana. The study however reveals some challenges such as affordance, access to mobiles devices and irregular power supply that need to be addressed in order not to exacerbate the problem of digital divide.
\end{abstract}

\section{Keywords}

ICT, Social media, Online networking, Pedagogy, Technology mediated teaching, Learning experience

\section{INTRODUCTION}

Technology mediated teaching and learning process at all levels of educational framework is getting expanding consideration by educational modules designers. Technology is considered to be a major impetus in the economic advancement of a country and any country that aims to position itself to confront the challenges of this 21 st Century and years to come will have to give high priority to education, science and technology. In the light of this, providing the citizenry with IT skills and technical know-how becomes very important.

The Government of Ghana in the past decade has given recognition to the requirement for ICT skills training and instruction in schools, colleges and universities and the enhancement of the education training framework at large as outlined in the government Information and Communication Technology For Development Agenda (ICT4D) agenda. The application of ICT in education is expected to generate better approaches to acquiring knowledge and learning analytics and improved outcomes for learners and instructors. ICT can also improve access to information and education [21]

ICTs do not involuntarily add quality to educating and learning process however, the utilization of value delivery technique for instructing is a noteworthy sympathy toward a fruitful use of ICT tools in teaching and learning. This study is purposed to explore how the incorporation some of the recent learning technologies, that is the social media into 'traditional' pedagogies will affect the teaching and learning with respect to motivation, performance and learning experience at the second cycle schools.

\section{LITERATURE REVIEW}

With the appearance of online networking technologies, educational leaders and teachers are tested with propelling, utilizing, and instructing an assortment of computerized tools across over different digital platforms. The previous five years have seen more than 50 distributed pieces on the significance of specialized communicators' utilizing online networking sites, for example, text messaging, instant messaging, micro blogging, image-sharing, and different mobile applications ([1]; [2]; [5]).

\subsection{Role of Technology in Teaching and Learning}

There is no doubt in the fact that ICT is hypothetically changing the landscape of both content and pedagogy which core issues in the $21^{\text {st }}$ century educational reform [11]. [21] argues that technology enables more effective learning when properly utilized and technology-mediated learning can advance the achievement of knowledge and the needed skills to equip students for lifelong learning if designed and implemented properly. ICTs, especially computers and Internet technologies can facilitate new ways to pursue teaching and learning instead of simply allowing teachers and students to improve on old methods [20]. Thijs, A. et al. (2002) cited in [20] highlights five aspects in which ICTs can help transform learning environment from teacher-centered to learner-centered and enhance deep knowledge and skills acquisition. These are active learning, collaborative learning, creative learning, integrative learning, and evaluative learning. Table 2.1 highlights these aspects in the traditional pedagogy and an emerging pedagogy enabled by ICTs. 


\begin{tabular}{|c|c|c|}
\hline Aspect & Less ('traditional pedagogy') & $\begin{array}{l}\text { More } \\
\text { ('emerging pedagogy' for the information society) }\end{array}$ \\
\hline Active & $\begin{array}{l}\text { - } \quad \text { Activities prescribed by teacher } \\
\text { - } \quad \text { Lhole class instruction } \\
\text { - } \quad \text { Pace determined by the programme }\end{array}$ & $\begin{array}{l}\text { - } \quad \text { Activities determined by learners } \\
\text { - } \quad \text { Small groups } \\
\text { - } \quad \text { Many different activities } \\
\text { - } \quad \text { Pace determined by learners }\end{array}$ \\
\hline Collaborative & $\begin{array}{ll}\text { - } & \text { Individual } \\
\text { - } & \text { Homogenous groups } \\
\text { Everyone for him/herself }\end{array}$ & $\begin{array}{ll}\text { - } & \text { Working in teams } \\
\text { - } & \text { Heterogeneous group } \\
\text { - } & \text { Supporting each other }\end{array}$ \\
\hline \multirow[t]{2}{*}{ Integrative } & $\begin{array}{ll}\text { - } & \text { Reproductive learning } \\
\text { - } & \text { Apply known solutions to problems }\end{array}$ & $\begin{array}{ll}\text { - } & \text { Productive learning } \\
\text { - } & \text { Find new solutions to problems }\end{array}$ \\
\hline & $\begin{array}{l}\text { - } \quad \text { No link between theory and practice } \\
\text { - } \quad \text { Separate subjects } \\
\text { - } \quad \text { Discipline-based } \\
\text { - } \quad \text { Individual teachers }\end{array}$ & $\begin{array}{l}\text { - } \quad \text { Integrating theory and practice } \\
\text { - } \quad \text { Relations between subjects } \\
\text { - } \quad \text { Thematic } \\
\text { Teams of teachers }\end{array}$ \\
\hline Evaluative & $\begin{array}{l}\text { - } \quad \text { Teacher-directed } \\
\text { - Summative }\end{array}$ & $\begin{array}{l}\text { - } \quad \text { Student-directed } \\
\text { - } \quad \text { Diagnostic }\end{array}$ \\
\hline
\end{tabular}

Table 2.1 Comparison between the traditional pedagogy and an emerging pedagogy enabled by ICTs. (Thijs, A., et al. cited in Tonio (2002)

Learning experience of students can be greatly enhanced if provided with modern ICT tools such as email, chatting facility, and discussion forum in virtual learning environment. However, technology have to be used in proper context if it is to have the desirable effect. A learning tool should be evaluated in the light of learning objective and the tool provided for use must match the desired learning outcome. [21]) opines that technology need to be used to connect with students and not to overwhelm students. For example, in the initial part of a course when students need to think through course assignment, a threaded discussion may be introduced. As the course progresses and students are required to devise solutions to problems, a chat tool or email could be used for submissions and feedback. Gradual introduction to the use of different tools in this way allows the students to orient themselves to the technology and not get inundated.

\subsection{Integrating Social Media into Classroom Pedagogy}

The term, social media is often used to refer to online networking characterized as media that are utilized for social connection, utilizing profoundly available and versatile correspondence methods. Online networking describes "a gathering of Internet-construct applications that works in light of the ideological and innovative establishments of Web 2.0, which permits the creation and trade of client generated content" [17].

A careful survey revealed dozens of research studies in which social media applications like wikis, YouTube, Facebook, Twitter, and LinkedIn played a significant role in gathering, measuring, and/or distributing information among technical and professional communicators ([3]; [8]; [10]; [12]). Summarily, the articles cited above argue that technical and professional communicators have the potential to act as key decision-makers as organizations adapt to social media use as part of their daily communications routines (Hockenhull et al, 2013) and perhaps for competitive advantages.

Also, the deployment of socially-networked tools across a multitude of digital spaces tends to cause users to assume that like magic, social media will augment classroom space and time, help spread information of the program and increase access. Today, the improvement and presentation of new correspondence advancements offers both the learner and the teacher chance to hunt down rich resourceful educational materials and in addition to interact decidedly and continuously from various locations [17]. Web applications such as social media can have a proportional association with education. The development of these innovations push teachers to appreciating and utilizing these digital tools for classroom use. In the meantime, the basic process of executing these digital tools in the classroom can specifically affect how these technologies keep on taking shape [15]. Youth today are profoundly drawn in and frequently learn freely or in a joint effort with their companions by means of innovation. Research demonstrates that adolescent adapts distinctively with social networking and online digital social media platforms, and therefore, the requirement for more adaptable instruction and online collaboration has become inevitable ([6]; [13]).

Unfortunately, this shift in paradigm could be seen to be destructive and be met with resistance from teachers, administrators and even some learners. Such resistance is often tied to assumptions and perceived limitations of digital literacy, privacy, and usefulness. There is a perspective that online networking can be utilized, approved, and executed effectively when its champions are discerning deliberately, not simply strategically. It is worth noting that these procedures ought to be founded on pragmatic assumptions about what instructors and learners alike can add to educational programs that incorporates social media instruments.

Furthermore, we offer concrete ideas that are informed by the best research on literacy, learning, and digital technologies and grounded in our own experiences using social media tools and technologies as students, teachers, and program leaders. In perspective of these, this research aims to highlight the utilization of social media platform to augment instructing and learning in second cycle schools in Ghana.

\section{METHODOLOGY}

Qualitative case study method was selected as a reasonable methodology for this study. [7] consider qualitative case study to be a multi-technique sort of exploration that uses an interpretive and practical methodology to prosecute its topic and also an accentuation on the characteristics of elements (i.e., procedures and implications happening actually) [18]. Besides, case study as subjective exploration can give powerful bits of knowledge from activities that have happened in a natural setting and preserve the proposed meaning which frames a 
comprehension of hidden social procedures and significance in a research setting, all of which would be hard to create from a quantitative exploration point of view (Mannen, 1998). Advantage of subjective examination is that since it can highlight the hidden human collaborations, implications and connections among variables in the experiences, it can possibly refine the hypothesis that is frequently surveyed in that area of thought. The case study technique was used as qualitative research approach in this study due to its potential to ascertains facts, analyzes them and draws inferences and establishes general principles.

The study utilized more of the subjective exploration technique with structured interviews and observation to gather information on the utilization and effect of social media on the teaching and learning processes in a selected public Senior High School. Namong SHS was selected and qualitative case study research method was adapted for the study. A case study research defines a thorough investigation of a single phenomenon or object such as an individual, a framework, a body, a group or a course. Extensive data are gathered about the individual object elected for study so that what is observed is a representative of the objects observed in all similar cases.

Since it is difficult to add to a significant comprehension of human experience without considering the exchange of qualities and convictions, subjective examination is said to be an interpretive naturalistic way to deal with the world [7]. This implies subjective analysts study things in their normal settings, endeavoring to comprehend or translate phenomena regarding the implications individuals convey to them. Keeping in mind the end goal to know precisely what sort of social media are utilized and the effect these have on students in the classrooms where they are utilized as a case of the public Senior High Schools in Ghana. Therefore, a subjective exploration technique such as case study which according to [9] examines the nature of relations, activities and circumstances, was utilized in this study. Interviews conducted were transcribed and composed into three phases of sorting out subjective information as suggested by Strauss and Corbin (1998).
The sample for the implementation of the research project consist of Students at Namong Senior High Technical School and drawn from SHS 2 and 3. The study adapts purposive sampling to select participants for the study. The researcher considers this as most appropriate due to the fact that researcher has no control over the entire population but just the classes under her tutorship. As such the intervention was applied only in the SHS2 and SHS3 classes the researcher teaches. Out of the four (6) classes, three (3) were selected due to limited resources for the intervention. Sample size of 100 students was finally used for the research.

\subsection{Implementation}

A Facebook $\odot$, and WhatsApp $\odot$ groups were created and populated with all participants. Synchronous sessions were organized with majority consensus on the time thrice a week. Asynchronous SMS on all the three platforms went on 24/7 (24hr daily basis) throughout the implementation phase. Questions were raised at random or as 'matters arise' in course of SMS exchanges. Occasionally too, topics are decided on with conscious. However, all topics raised and discussed were based on the IT syllabus of the GES for the SHS and more particularly, current topic being discussed treated in class.

\subsubsection{Using Facebook To Support Teaching And Learning}

A customized Facebook group, Nastech SHS Social Media Class was created with teacher as the administrator and students were added onto the group for participation in the 'extended' classroom sessions and to also collaborate with their peers. It allows the teacher to post lesson notes, assignments and quizzes notice as well as to initiate a forum. Students could request for further explanation to some lessons taught in class. They could post responses to assignments online and also perform live chat live the teacher and peers on the platform. Figure 3.1 below indicate various sections of lessons discussion on the Facebook group platform.

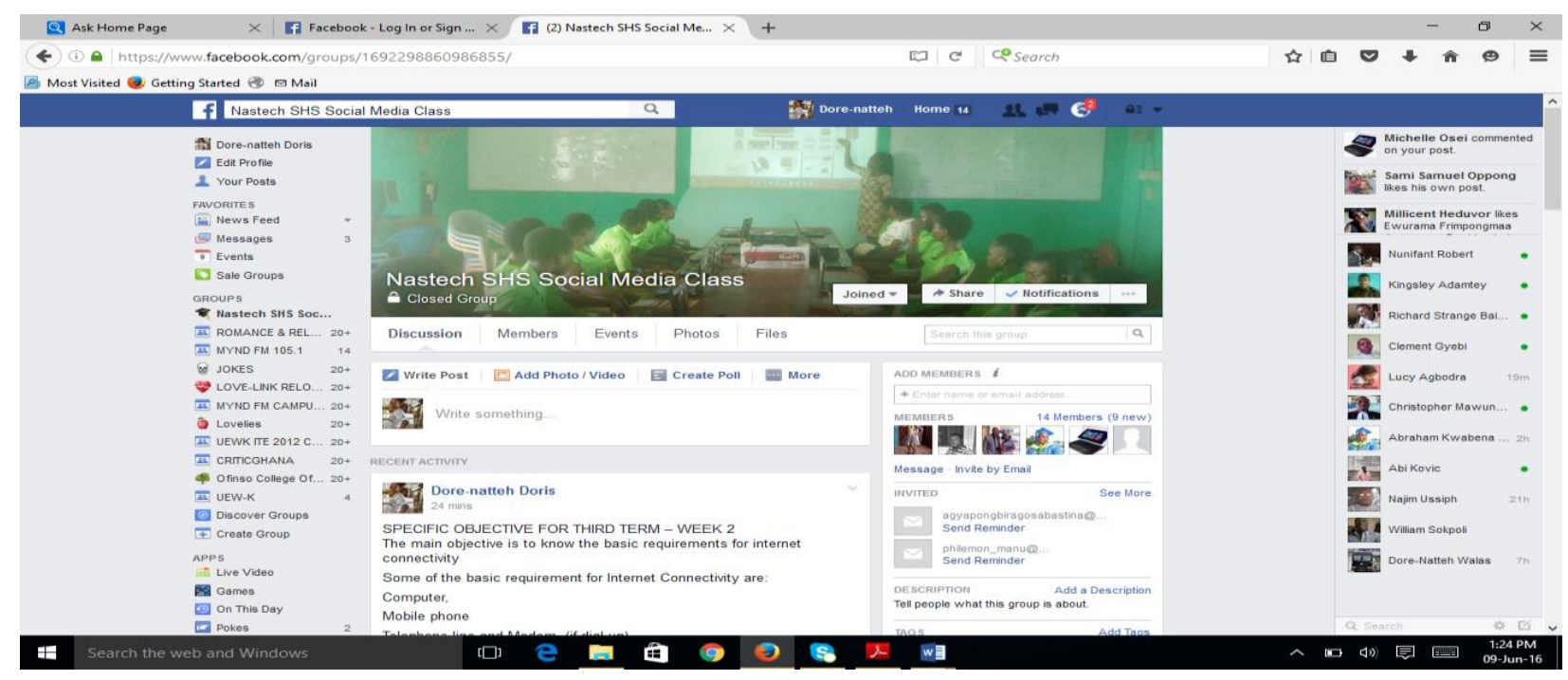

Figure 3.1 Nastech SHS Social Media class page 


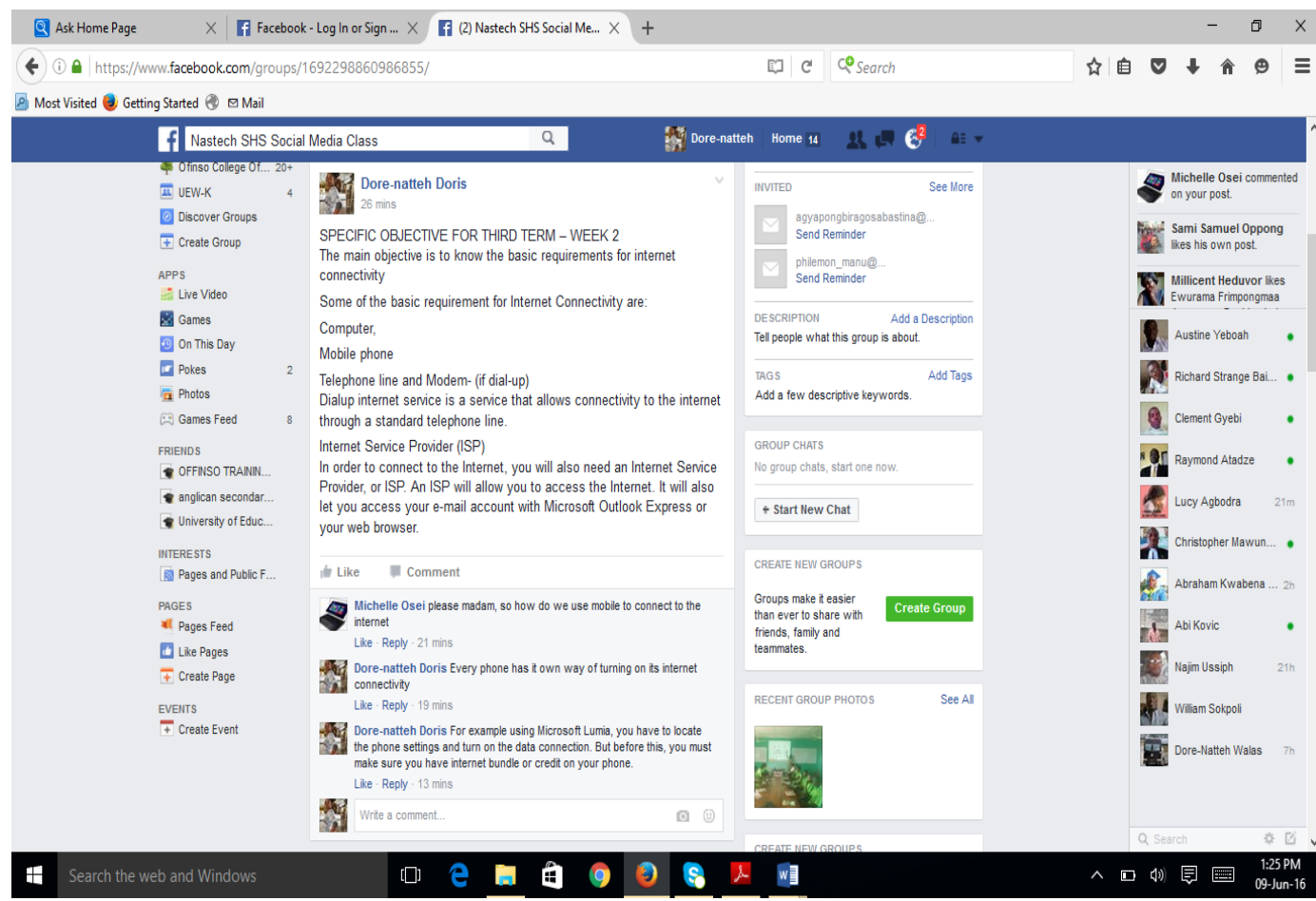

Figure 3.2 Discussion session on the platform

\subsubsection{Using Whatsapp To Support Teaching And Learning}

The utilization of cell phones with their internet access, together with the influence of social networking sites, offers a resourceful stage for creative student-centered learning experiences. The usage of WhatsApp mobile application has become one of the preferred methods of communication with students. Adopting this mode of communication is flexible because most students are familiar with smart phones and its application usage. In particular, WhatsApp's has the ability for eliminating boundaries between formal and informal education, between educational and social life, between informal learning setting and the traditional classroom, between experts. Figure 3.3 illustrates the interface of the WhatsApp platform for NASTECH SHS.

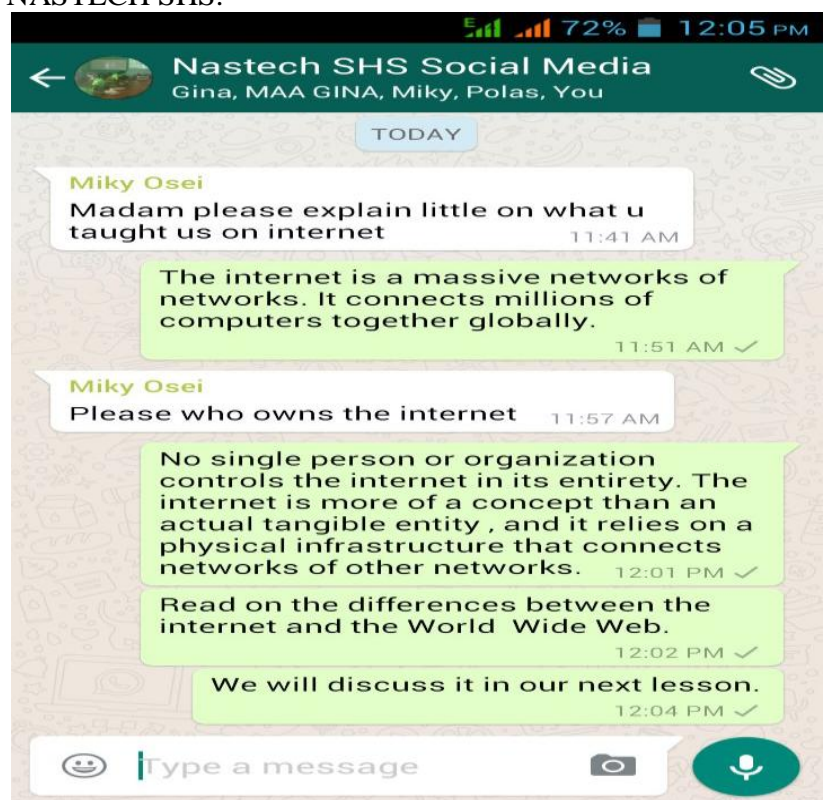

Figure 3.3 Discussion between the teacher and students on WhatsApp

\subsection{Data Gathering And Analysis Process}

This study employed participatory observation and structured interview methods to gather data from the implementation of the research project. The target behavior was clearly and explicitly defined with the help of an observational guide. Employing participatory observational method implies that the researcher was physically "immersed" in the project the designer and resource person for the subject. All the participants were interviewed. They were asked same set of questions (see Appendix A) and almost the same way but given freedom to express themselves in whatever way they desired.

Research diary was kept to record observations throughout the implantations period for independent judgement of the flow of events during sessions and interactions. The research dairy serves as a helpful instrument in qualitative research. It can be utilized by researcher whether their primary interest is research, proficient practice or social change. The dairy serves as auxiliary source to compliment other information accumulated from personal observation, interviews or focus groups. Participants were issued a sample of the interview questions to study before starting the actual interview so as to get familiar with questions beforehand and opportunity for researcher to explain any difficult point in the set of questions.

The study used computer-assisted qualitative data analysis (CAQDAS) for analyzing the data. Transcribed interview sources were fed into NVIVO, the software for the analysis. Features of the software were then applied to reveal outcomes in a proven scientific manner for the outcome to stand the test of validity and rigor.

\subsubsection{Analysis Of Data}

Data from this project were gathered using researcher's documented observations in memo and interviews (see Appendix A for interview questions). Qualitative analysis software, Nvivo was employed in the data analysis. Participant's responses were fed into Nvivo as source files (Figure 3.4). 


\begin{tabular}{|c|c|c|c|c|c|c|c|c|}
\hline \multirow{3}{*}{$\begin{array}{l}\text { Sources } \\
\square \text { Internals } \\
\text { Interviews }\end{array}$} & Look for: & v & - Interviews & Find Now & Clear & Advanced Find & & \\
\hline & \multicolumn{8}{|l|}{ Interviews } \\
\hline & Name & Nodes & References & Created On & & Created By & Modified On & Modified By \\
\hline Memos & Participant1 & 9 & 13 & 09-Jun-16 7:33 PM & & D & 09-Jun-16 7:33 PM & \\
\hline \multirow{13}{*}{ Framework Matrices } & Participant10 & 11 & 11 & 09-Jun-16 7:33 PM & & D & 09-Jun-16 7:33 PM & D \\
\hline & D. Participant11 & 9 & 12 & 09-Jun-16 7:33 PM & & D & 10-Jun-16 1:34 PM & D \\
\hline & (1) Participant12 & 13 & 13 & 09-Jun-16 7:33 PM & & D & 09-Jun-16 7:33 PM & D \\
\hline & Participant13 & 12 & 13 & 09-Jun-16 7:33 PM & & D & 09-Jun-16 7:33 PM & D \\
\hline & (1) Participant14 & 10 & 11 & 09-Jun-16 7:33 PM & & D & 09-Jun-16 7:33 PM & D \\
\hline & Participant15 & 12 & 12 & 10-Jun-16 2:26 PM & & D & 10-Jun-16 2:26 PM & D \\
\hline & Participant16 & 13 & 13 & 10-Jun-16 2:28 PM & & D & 10-Jun-16 2:57 PM & D \\
\hline & Participant17 & 12 & 13 & 10-Jun-16 3:07 PM & & D & 11-Jun-16 4:08 PM & D \\
\hline & Participant18 & 9 & 9 & 10-Jun-16 3:08 PM & & D & 11-Jun-16 4:20 PM & D \\
\hline & (1) Participant19 & 12 & 12 & 13-Jun-16 1:38 AM & & D & 13-Jun-16 1:38 AM & D \\
\hline & Participant2 & 7 & 8 & 09-Jun-16 7:33 PM & & D & 09-Jun-16 7:33 PM & D \\
\hline & (1) Participantz20 & 9 & 10 & 13-Jun-16 1:39 AM & & D & 13-Jun-16 1:39 AM & D \\
\hline & Participant21 & 10 & 11 & 13-Jun-16 1:39 AM & & D & 13-Jun-16 1:39 AM & D \\
\hline \multirow{2}{*}{ Sources } & (1) Participant222 & 11 & 12 & 13-Jun-16 1:40 AM & & D & 13-Jun-16 1:40 AM & D \\
\hline & (D) Participant23 & 10 & 11 & 13-Jun-16 1:41 AM & & D & 13-Jun-16 1:41 AM & D \\
\hline \multirow{2}{*}{ Nodes } & Darticipant24 & 10 & 12 & 13-Jun-16 1:41 AM & & D & 13-Jun-16 1:41 AM & D \\
\hline & Participant25 & 8 & 9 & 13-Jun-16 2:23 AM & & D & 13-Jun-16 2:23 AM & D \\
\hline \multirow[t]{2}{*}{ (4) Classifications } & Participant26 & 8 & 9 & 13-Jun-16 2:24 AM & & D & 13-Jun-16 2:24 AM & D \\
\hline & Participannt27 & 9 & 10 & 13-Jun-162:24 AM & & D & 13-Jun-16 2:24 AM & D \\
\hline \multirow[t]{2}{*}{17 collections } & (1) Participant28 & 10 & 12 & 13-Jun-16 2:25 AM & & D & 13-Jun-16 2:25 AM & D \\
\hline & Participant29 & 10 & 11 & 13-Jun-16 2:26 AM & & D & 13-Jun-16 2:26 AM & D \\
\hline D. Queries & Participant3 & 7 & 9 & 09-Jun-16 7:33 PM & & D & 09-Jun-16 7:33 PM & D \\
\hline \multirow{2}{*}{ [ Reports } & Participant30 & 8 & 10 & 13-Jun-16 2:26 AM & & D & 13-Jun-16 2:26 AM & D \\
\hline & participant31 & 8 & 9 & 13-Jun-16 3:34 AM & & D & 13-Jun-16 5:31 PM & D \\
\hline \multirow[t]{2}{*}{9 Models } & participant32 & 11 & 11 & 13-Jun-16 3:35 AM & & D & 13-Jun-16 5:31 PM & D \\
\hline & D. Participantz3 & 12 & 14 & 13-Jun-16 3:36 AM & & D & 13-Jun-16 5:50 PM & D \\
\hline \multirow{3}{*}{ folders } & participant34 & 11 & 12 & 13-Jun-16 3:36 AM & & D & 13-Jun-16 5:33 PM & D \\
\hline & participant35 & 12 & 13 & 13-Jun-16 3:37 AM & & D & 13-Jun-16 5:33 PM & D \\
\hline & participant36 & 9 & 12 & 13-Jun-16 3:38 AM & & D & 13-Jun-16 5:32 PM & D \\
\hline
\end{tabular}

\section{Figure 3.4 Participants' interviews from Group A as sources in Nvivo}

It is important to indicate here that only interviews scripts of participants were coded. Observations of the researcher were mainly used to make modifications in tasks and processes in the implementation. Upon scrutinizing the interview scripts and pondering on researcher's memos from the research diary entries and observations, issues that came from the data gathering stage could be summarized into eight main themes which includes affect, learning experience, motivation, affordance, acceptance, availability, challenges and recommendation (Figure 3.5). It is also worth mentioning here that this study was originally undertaken for a Master Degree thesis, however, this paper is only based on the examination of the impacts of the application of social media in teaching and learning in respect of motivation, performance and learning experience of students.
The analysis of data applies the content analysis technique [14] of the fundamental subjective exploration and information gathering strategies. At the final stage, the outcomes are exhibited in a way that depicts the important result of the examination to answer the exploration questions postured. The finished item from the massive data analysis examination is referred to as "the big picture" (Hancock, 2002:17 cited in [21] or major findings. It is however essential to specify that there might be some quantifiable amounts or values expressed; the investigation was basically subjective and included content information or words that depict a phenomenon and describing their implications in a manner that prompts further understanding and occasionally new actualities or ideas.

\begin{tabular}{|c|c|c|c|c|c|c|c|c|}
\hline Nodes & Look for: & r & Search In & - Nodes & Find Now & Clear & Advanced Find & $\mathrm{x}$ \\
\hline $\begin{array}{l}\text { (1) Nodes } \\
\text { (3) Relationships }\end{array}$ & Nodes & & & & & & & \\
\hline Zal Node Matrices & $\begin{array}{l}\text { Name } \\
\boxminus O^{\text {Adaptability }}\end{array}$ & $\begin{array}{l}\text { B Sources } \\
47\end{array}$ & $\begin{array}{l}\text { References } \\
47\end{array}$ & $\begin{array}{l}\text { Created On } \\
\text { 09-Jun-16 8:04 PM }\end{array}$ & $\begin{array}{l}\text { Created By } \\
\text { D }\end{array}$ & $\begin{array}{l}\text { Modified On } \\
\text { 14-Jun-16 5:12 PM }\end{array}$ & $\begin{array}{l}\text { Modified By } \\
\text { D }\end{array}$ & 围 \\
\hline & Acceptance & 7 & 7 & 14. Jun-163.37 PM & 0 & 14-Jun-16 3.47 PM & D & \\
\hline & 10 Affect & 47 & 53 & 09-Jun-16 7:48 PM & D & 11-Jun-16 4:02 PM & D & ש \\
\hline & Effectiven & 13 & 13 & 09-Jun-16 7:50 PM & D & 13.Jun-16 5:33 PM & D & 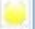 \\
\hline & (1) Efficiency & 36 & 38 & 09-Jun-16 7.50 PM & D & 13.Jun-16 5:-33 PM & D & ( \\
\hline & Diffic & 6 & 6 & 09-Jun-16 7:52 PM & D & 13-Jun-16 5:31 PM & D & \\
\hline & Oasy & 4 & 5 & O9-Jun-16 7:51 PM & D & 10-Jun-16 1:35 PM & D & \\
\hline & Mode & 5 & 5 & O9-Jun-16 7:52 PM & D & 13-Jun-16 5:33 PM & 0 & \\
\hline & E $O$ Affordance & 36 & 53 & $09-\sqrt{ }$ un- $167.48 \mathrm{PM}$ & D & 14-Jun-163:30 PM & D & ( \\
\hline & Affordabl & 13 & 13 & 14-Jun-16 2.55 PM & 0 & 14.Vun-16 3.47 PM & D & \\
\hline & Not Affor & 30 & 47 & 10-Jun-16 11:44 AM & D & 14.Jun-16 3:15 PM & D & \\
\hline & EO Availability & 30 & 33 & 09-Jun-16 7:49 PM & D & 13-Jun-165:33 PM & D & (a) \\
\hline & Available & 26 & 26 & 14-Jun-16 2:57 PM & D & 14.Jun-16 3:20 PM & D & \\
\hline & Not Avail & 2 & 3 & 14-Jun-16 2:58 PM & D & 14-Jun-16 3.06 PM & D & \\
\hline Sources & Challenges & 48 & 49 & 14-Jun-16 4:14 PM & D & 14.Jun-16 4:15 PM & D & \\
\hline & Learning Exp & 48 & 52 & 09-Jun-16 8:00 PM & D & 14-Jun-16 4:35 PM & D & \\
\hline Nodes & Motivation & 40 & 43 & 09-Vun-167.47 FM & D & 14-Jun-16 5:11 PM & D & - \\
\hline lassifications & E $O$ Recommend & 49 & 55 & 09-Jun-16 8:08 PM & D & 14-Jun-16 4:44 PM & D & \\
\hline & Negative & 11 & 12 & 14.Jun-16 4:23 PM & D & 14 V vun-16 5.01 PM & D & \\
\hline Collections & 0 Positive & 23 & 25 & 14: Jun $164: 23 \mathrm{PM}$ & D & 14. Jun- $165: 03 \mathrm{PM}$ & D & \\
\hline D Queries & & & & & & & & \\
\hline [ Reports & & & & & & & & \\
\hline
\end{tabular}

Figure 3.5 Themes/subjects used as Nodes in Nvivo 


\section{FINDINGS}

This section interrogates data gathered from the interviews of Participants on adapting the Social Media into the delivery of teaching and learning having attempted to migrate classroom discussions and tutorials onto Facebook and WhatsApp groups. The impact of this innovation on motivation and learning experience among others from the perspective of the students were enquired. The Performance metric was left in the hand of the researcher as the participants could not assess their performance on their own.

\subsection{Motivation}

Motivation used in the context of this study measures the enthusiasm that the new learning method provides. This measured was determined from the responses of the participants coded at the Motivation node. Majority of participants attested to the fact that the method was very enthusiastic and that served as a good motivation for them to always want to access the content on the social media platform and participate in a forum more that they would with the traditional lessons in the classroom. Overwhelming majority of up $80 \%$ of participants agreed to this (Figure 4.1)

\subsection{Learning Experience}

Learning experience alludes to any communication, course, program, or other involvement in which learning happens, whether it happens in traditional school/classroom settings or nontraditional settings (outside-of-school areas, open space locations), or whether it incorporates conventional instructive interactions (students gaining from instructors and teachers) or nontraditional collaborations (understudies learning through diversions and intelligent computer applications). It underscores or fortifies the objective of an instructive collaboration, adapting instead of its area (school, classroom) or outline (course, program). In another context it is a measure of how convenient, smooth, and / or exciting a pedagogical method is considered to be. This is the context in which learning experience is used in this study. Participant overwhelmingly attested to the fact that using the social media in supporting classroom lessons provides them with very rich learning experience. They see it to be another way of 'injecting life' into the task of learning. Figure 4.2 shows the massive response of the participants at the node

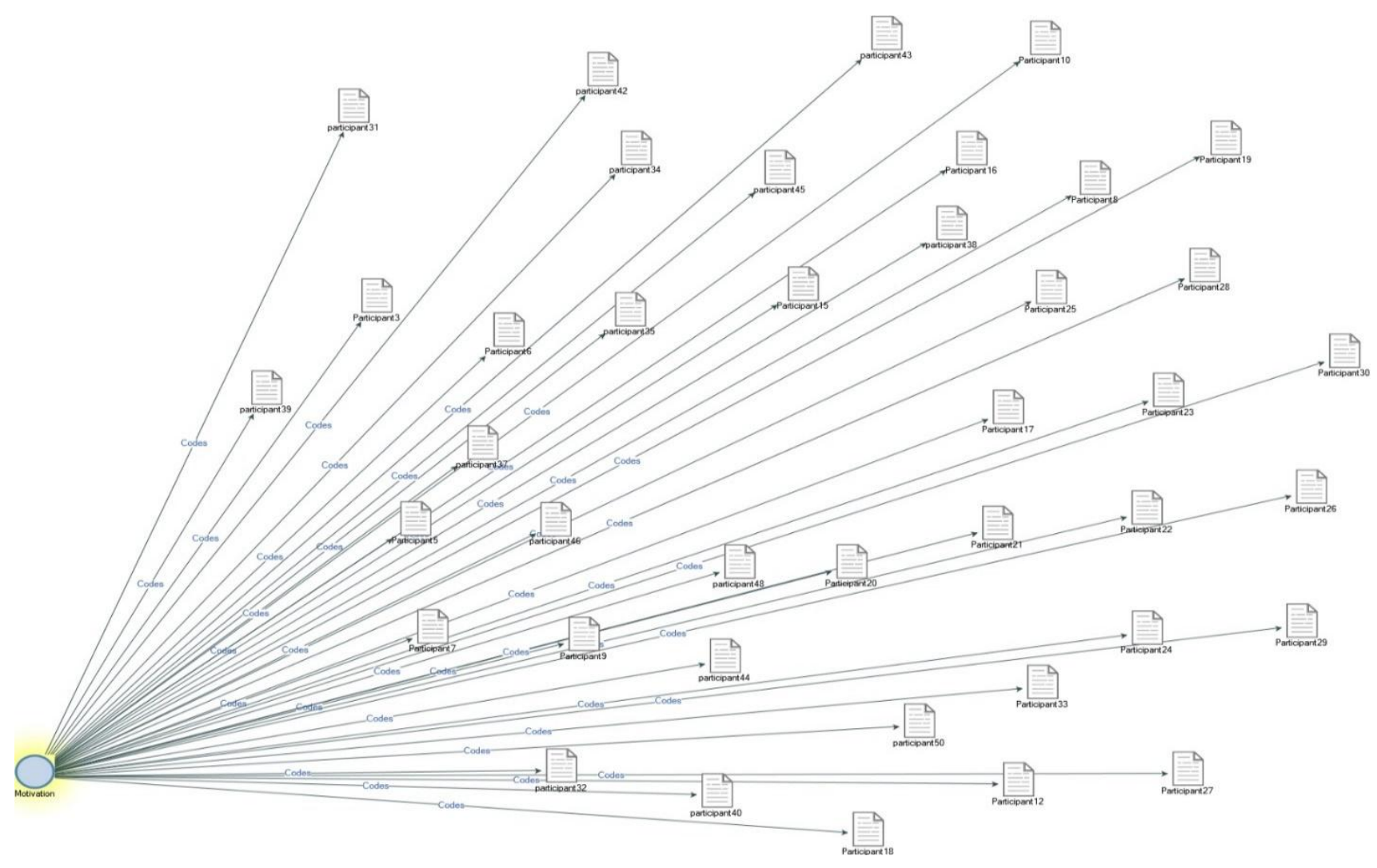

Figure 4.1 Showing coding density at Motivation node 


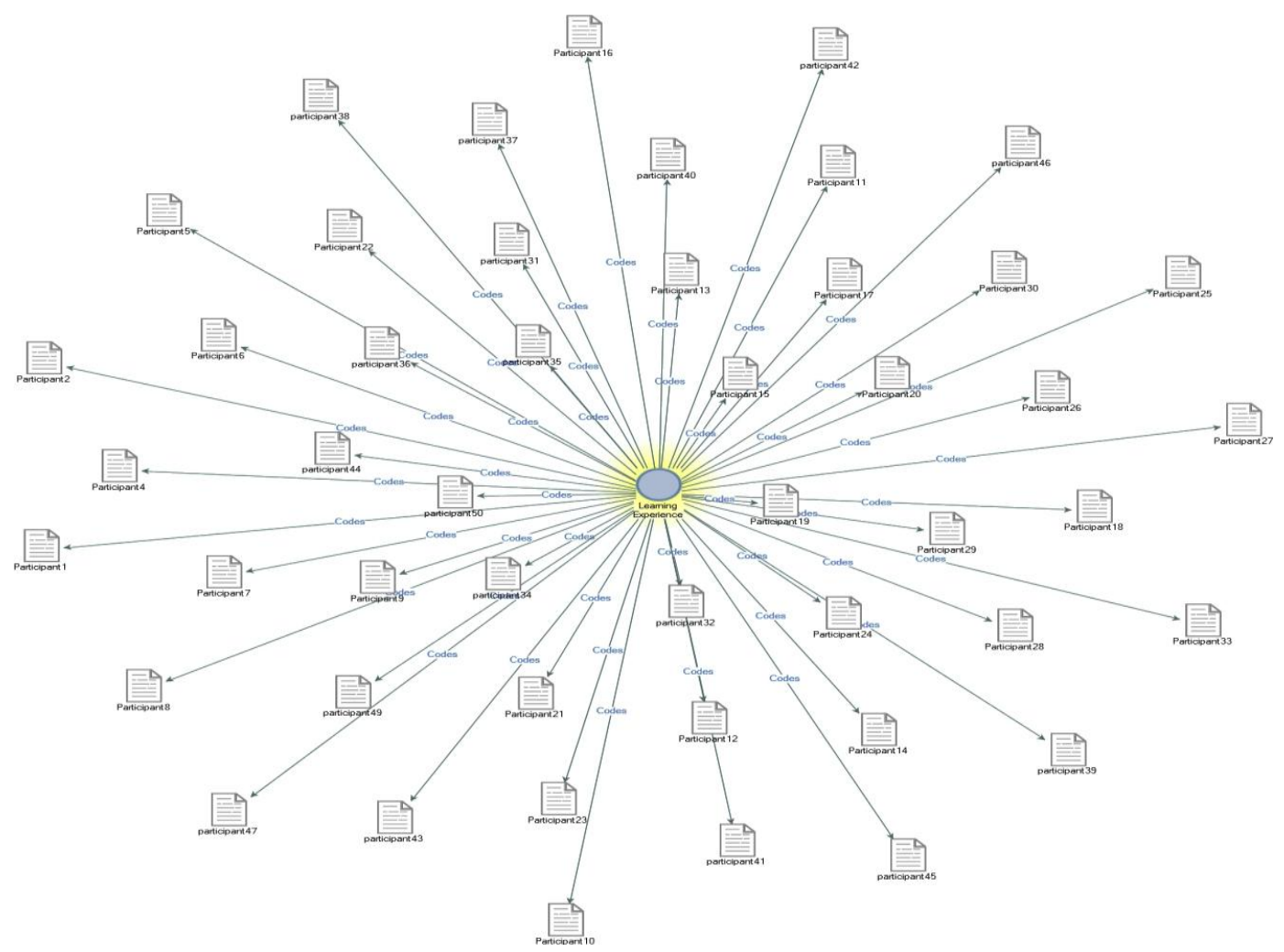

Figure 4.2 Showing density of code at the Learning Experience node

\subsection{Performance}

Evaluation of the effect of the new method on Performance was left in the hands of the researcher as the participants could not assess their performance on their own. The researcher made notes in the research memo on individual participants' performance at end of the terminal examination and compared the performances in ICT subject for the term, which was supported with the social media platform and previous term in which only the traditional method was used. Data from the memo was part of the sources fed into Nvivo and was coded.

It turned out from the analysis that majority of the participants approximately fifty percent - improved in performance for the subject while about twenty percent of the participants recorded a decline in performance. Performance of about a third, approximately thirty-three percent remained unchanged (see Figure 4.3).

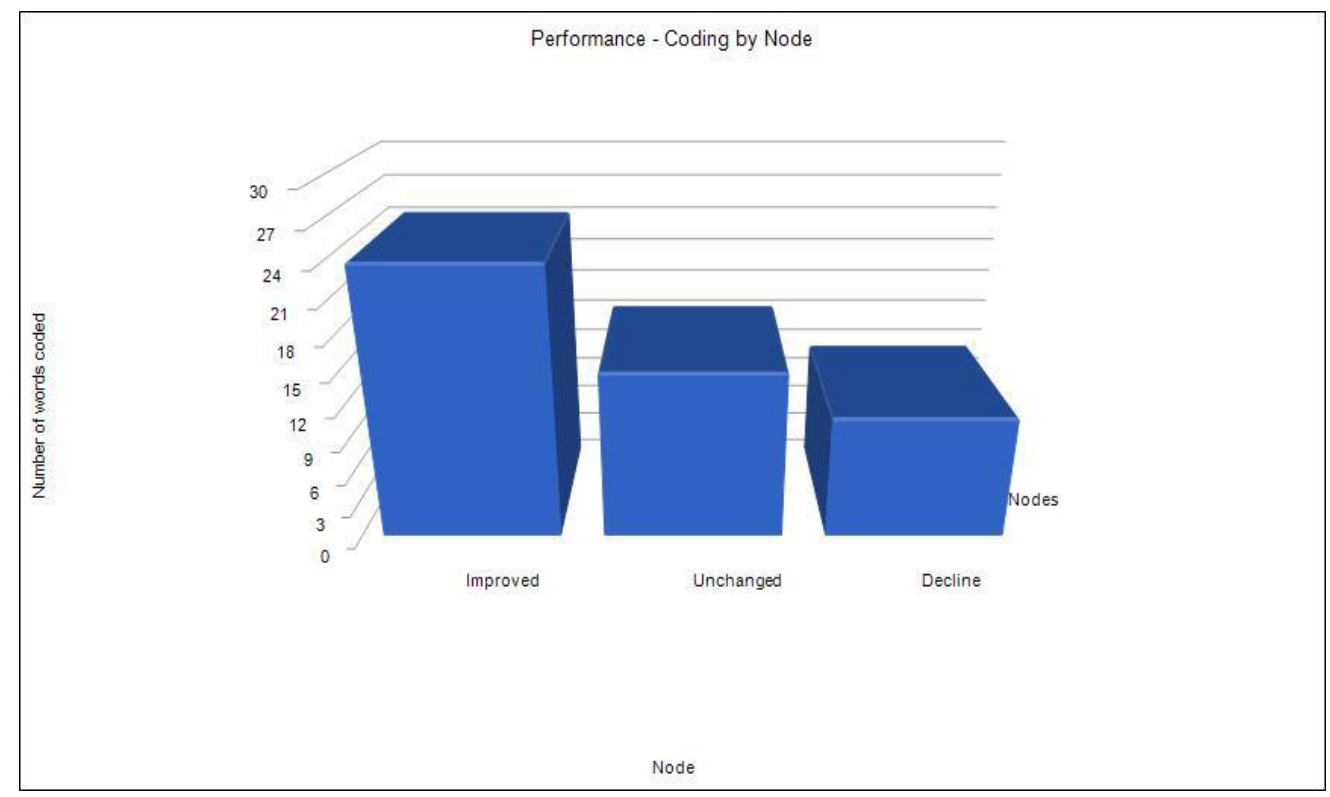

Figure 4.3 showing coding at Performance nodes 


\section{DISCUSSION}

This discussion examines the findings within the context of literature to uncover similarities which support theory and differences, thus allowing this research to reveal new insight into supplementing teaching and learning process to inform theory on the adaptation and effects of social media in teaching and learning.

It was argued in the literature that integrating social media to classroom learning brings more effective and enhance the acquisition of knowledge and skills needed for lifelong learning [16]. Technology-driven studies also brings new methods of teaching and learning and not just enabling students and teachers to do same thing in appropriately but also provides more resourceful ways of reaching vital information to promote their studies [15]. Findings from this study attested to these views. Features such as active learning, collaboration, and learning experience are inherent in technology-driven learning and these were manifested in the outcome of this study. Students confirmed to how the novel way of delivering tutorial support has helped them to become better students by gaining information searching skills to access rich information outside the classroom to enhance their learning experience. They were able to search for further materials on their own and developed new or alternative solutions to problems.

Students from this study showed increase level of collaborative skills and easy adaptation of social media to enhance traditional classroom learning. There was also overall conclusion that their learning experiences with the new teaching approach have improved tremendously. Motivational impact with the introduction of the social media platforms was considered as impetus in their yearning for longer learning periods. In fact, motivational effect was found to be very high as seen in (Figure 5.9) this study

Analysis from the study showed that students were able to quickly adapt to the social media platform and found it easier to use. The study also demonstrated that the intervention method did improve the teaching and learning process tremendously with the introduction of social media platforms to augment classroom lessons.

Later analysis of the outcome on performance by the researcher revealed that majority of the participants - approximately fifty percent - improved in performance for the subject while about twenty percent of the participants recorded a decline in performance. Performance of about a third, approximately thirty-three percent remained unchanged (see Figure 5.16). Thus, outcome of this research confirms the results of the study by [4] demonstrating that WhatsApp mobile learning activities brings a lot of positive effects on students' success and attitudes towards online teaching and learning.

\subsection{Summary and Conclusion}

In conclusion, the augmentation of the social media to support classroom teaching as done in this study has proven to have potential in bringing the needed change in paradigm to classroom pedagogy in this digital age. The blending of pedagogies that leads to the notion of 'blended learning' - a modern way of blending traditional method with e-learning would greatly enhance the way this generation of learners prefer to learn and understand learning. Technology-driven learning features such as active learning, collaborative and problembased learning can enrich learning skills and enhance learning experience as shown in the outcome of this study. Students confirmed that the new way of delivering tutorial support has helped them to become better learners by being able to access rich information to heighten their learning experience. They were able to source for further materials on their own and provide alternative solutions to problems. There was also general conclusion that their learning experiences with the new teaching approach have been positive.

Additionally, integrating social media platform into classroom teaching has been proven to be effective and efficient in respect of ease of use and availability. The system can be available and accessible round the clock. However, there could be some technical hitches or inadequate facilities that may impede the system such as irregular power supply, access or affordability of devices and internet connectivity down times.

\section{REFERENCES}

[1] Abel, S. (2011). The Future of technical communication is socially enabled: Understanding the Help 2.0 revolution. Intercom, 58(4), 6-10.

[2] Baehr C. \& Henschel, Sally (2013). STC student membership: Challenges, opportunities, and benefits. Intercom, 60(1), 31-33.

[3] Ball, C. E. (2012). Assessing scholarly multimedia: A rhetorical genre studies approach. Technical Communication Quarterly, 21(1), 61-77. doi:1 $0.1080 / 10572252.2012 .626390$

[4] Barhoumi, C. (2015). The Effectiveness of WhatsApp Mobile Learning Activities Guided by Activity Theory on Students' Knowledge Management. Contemporary Educational Technology, 2015, 6(3), 221-238. Taibah University, Saudi Arabia.

[5] Barton, M. D., \& Heiman, J. R. (2012). Process, product, and potential: The archaeological assessment of collaborative, wiki-based student projects in the technical communication classroom. Technical Communication

[6] DeGennaro, D. (2008). Learning designs: An analysis of youth-initiated technology use. Journal of Research on Technology in Education. 41(1), 1-21.

[7] Denzin, N.K. \& Lincoln, Y.S. (eds) (2005) Handbook of Qualitative Research, 2nd edn. Thousand Oaks, Sage.

[8] Ding, Huiling. (2009). Rhetorics of alternative media in an emerging epidemic: SARS, Censorship, and Extrainstitutional risk communication. Technical Communication Quarterly, 19(4), 327-350. doi:10.1080/10572250903149548

[9] Fraenkel, J. R., \& Wallen, N. E. (2000). How to design and evaluate research in education $\left(4^{\text {th }}\right.$ ed.). Boston: McGraw Hill.

[10] Frost, E. A. (2013). Transcultural risk communication on Dauphin Island: An analysis of ironically located responses to the deep-water horizon disaster. Technical Communication Quarterly, 22(1), 50-66. doi:10.1080/10572252.2013.726483

[11] Garrison, D. R., \& Anderson, T. (2003). E-Learning in the 21st Century - A Framework for Research and Practice: RoutledgerFalmer Publishers, USA.

[12] Graham, S. Scott, \& Whalen, B. (2008). Mode, medium, and genre: A Case study of decisions in new-media design. Journal of Business and Technical Communication, 22(1), 65-91. doi:10.1177/1050651907307709 
[13] Ghorbani, N. R., \& Heidari, R. N. (2011). Effects of information and communication technology on youth's health knowledge. Asia Pacific Journal of Public Health, 23(3), 363-368. doi:10.1177/1010539509340435

[14] Hsieh, H-F and Shannon, S. E, (2005). Qualitative Health Research, Vol. 16 No. 9, 1277-1288 DOI: $10.1177 / 1049732305276687$

[15] Klopfer, E., Osterweil, S., Groff, J., \& Haas, J. (2009). The instructional power of digital games, social networking, simulations, and how teachers can leverage them. Cambridge, MA: The Education Arcade, Massachusetts Institute of Technology. http://education.mit.edu/papers/GamesSimsSocNets_EdAr cade.pdf

[16] Oloyede, B. (2008). Free Press and Society: Dismantling the Culture of Silence, Ibadan: Stirling-Horden Publishers Ltd.
[17] Oluwalanu, S. B., Omowale, A. and Kayode, O. J., (2014). Adapting Social Media for Formal Learning in Nigeria: Challenges and Prospects. Arabian Journal of Business and Management Review (OMAN Chapter) Vol. 3, No.9

[18] Richadson, L. (2000). Writing: A Method of Inquiry. In N. K. Denzin \& Y. S. Lincoln (Eds.), Handbook Qualitative Research (2nd ed.). Thousand Oaks.

[19] Straus, A., \& Corbin, J. (2008). Basics of Qualitative Resarch: Techniques and Procedures for Developing Grounded Theory (3rd ed.). London: Sage.

[20] Tonio, V. L. (2008). ICT In Education Retrieved from http://en.wikibooks.org/wiki /ICT_in_Education

[21] Ussiph, N. (2012). Using a Virtual Learning Environment to Support Teaching and Learning and to Bridge the Digital Divide Between Urban and Rural Communities in Ghana: An Action Case Study. Ph.D Thesis. University of Salford: Manchester. 